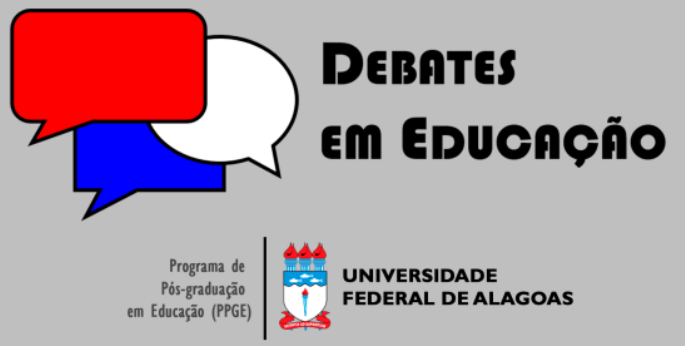

ISSN Eletrônico 2175-6600

Vol. 12 | No. 26 | Jan./Abr. | 2020

José Roberto Boettger Giardinetto

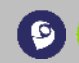

Universidade Estadual Paulista (UNESP) irbgiarj@gmail.com

\section{PEDAGOGIA HISTÓRICO-CRÍTICA E EDUCAÇÃO MATEMÁTICA: A \\ UTILIZAÇÃ̃O DE CATEGORIAS DO \\ MATERIALISMO HISTÓRICO-DIALÉTICO COMO SUBSÍDIO PARA O PROCESSO DE ENSINO}

\section{RESUMO}

A Pedagogia Histórico-crítica (PHC) é uma tendência pedagógica de fundamentação marxista e utiliza-se das categorias do materialismo histórico-dialético como referência para análise e melhoria do ensino. Este artigo promove uma reflexão sobre a aplicação de determinadas categorias como fundamentação para sistematização de procedimentos de ensino na Matemática. Assim, tecem-se considerações sobre as categorias do lógico e histórico, abstrato e concreto e singular, particular e universal.

Palavras-chave: Educação matemática. Pedagogia histórico-crítica. Categorias dialéticas.
}

\section{HISTORICAL-CRITICAL PEDAGOGY AND MATHEMATICAL EDUCATION: THE USE OF CATEGORIES OF HISTORICAL-DIALECTICAL MATERIALISM AS A SUBSIDY FOR THE TEACHING PROCESS}

\begin{abstract}
Historical-Critical Pedagogy (PHC) is a pedagogical tendency of Marxist foundation and uses the categories of historical-dialectical materialism as a reference for analysis and improvement of teaching. This article promotes a reflection about the application of certain categories as a basis for systematizing teaching procedures in Mathematics. Thus, considerations are made about the categories of logical and historical, abstract and concrete and singular, particular and universal.
\end{abstract}

Keywords: Mathematical education. Historical-critical pedagogy. Dialectical categories.

Submetido em: I1/03/2019

Aceito em: 15/10/2019

Publicado em: 06/04/2020

dc http://dx.doi.org/I0.28998/2 I 75-6600.2020v I 2n26p2 I | -224 


\section{INTRODUÇÃO}

A Pedagogia Histórico Crítica - PHC por ser uma pedagogia marxista, tem como referência a concepção marxista de conhecimento.

Para o indivíduo compreender a realidade precisa se instrumentalizar de uma lógica que permita entender a dinamicidade do real em suas múltiplas determinações. A lógica dialética é a lógica do movimento do real, é a lógica das relações. Segundo Duarte (| 987, p. | 8):

[...] assim como a realidade é dinâmica, está em constante movimento, o seu reflexo no pensamento, para poder guiar a ação humana, precisa ser também dinâmico, precisa ser orientado por categorias que deem conta dessa dinamicidade. Se a lógica objetiva é dialética, a lógica subjetiva também precisa ser dialética para que o homem possa dominar as leis de desenvolvimento do mundo objetivo. A utilização das categorias dialéticas na análise de um objeto de estudo não é apenas um mero modo de se ver as coisas. Também não é um modelo lógico dentro do qual se encaixe a realidade analisada. Mas, ao contrário, o que leva o pensamento a se guiar por essas categorias é o fato de que elas expressam o movimento da realidade a ser analisada.

Para Saviani (1985, p. 25), pensar de forma dialética "nos arma de um instrumento, ou seja, de um método rigoroso (crítico) capaz de nos propiciar a compreensão adequada da radicalidade e da globalidade na unidade da reflexão filosófica".

A lógica dialética permite pensar e entender as contradições, pois, instrumentaliza o indivíduo a pensar por contradição. Na visão de Oliveira (1994, p. 125):

[...] a concepção dialética da realidade social torna-se um instrumental lógico-metodológico com um sentido ético-políico, porque permite ao pensamento constatar o real movimento do processo que se dá dentro das relações sociais de produção e, desse modo, ser um instrumental que possibilita uma atuação mais crítica dentro da modalidade da pratica social em que atua, no caso, a educação. A dialética assim concebida por Saviani torna-se guia de pensamento, em método de ação, e de construção de conhecimento da realidade.

O desafio pedagógico para a PHC consiste em elaborar sequências de ensino e de aprendizagem que criem as condições para que o aluno se aproprie dessa "lógica das relações" no decorrer do processo de apropriação dos conteúdos escolares ou, dizendo de forma mais precisa, apreenda os conceitos enquanto relações.

O objetivo deste artigo é apresentar algumas reflexões que contribuam para o desenvolvimento e a execução de procedimentos de ensino na Matemática, que superem a concepção lógico formal da Matemática e do seu ensino, buscando, na lógica dialética, os subsídios para realizar um ensino de Matemática dinâmico que ressalte as relações entre seus conceitos. 


\section{CATEGORIAS DO MATERIALISMO HISTÓRICO-DIALÉTICO SUBSIDIANDO O ENSINO DA MATEMÁTICA}

Neste item, o objetivo é apresentar uma reflexão sobre as categorias do materialismo históricodialético que têm norteado as pesquisas desenvolvidas pelo autor deste artigo. Tratam-se das categorias: do lógico e do histórico; do abstrato e do concreto e das categorias do singular, particular e universal.

Entretanto, antes de adentrar nesta reflexão cumpre observar que considerações sobre a perspectiva dialética na Matemática e seu ensino já foram abordadas por Caio Prado Júnior ( 1907 - 1990), na obra "Dialética do Conhecimento" (PRADO Jr, | 952), bem como por Bento de Jesus Caraça ( 901 1948) e Francisco Vera ( 888 - 1967), assunto de análise específica. Apesar de se tratar de temática de um futuro trabalho, considerando os limites de páginas deste artigo, optamos em destacar algumas das reflexões desenvolvidas por Caio Prado Júnior.

Na obra "Dialética do Conhecimento", Prado, Jr (1952) tece considerações sobre a gênese da lógica dialética frente à metafísica. Aponta, em seus estudos, que o objeto do conhecimento metafísico são "individualidades" enquanto que o objeto de conhecimento do conhecimento dialético são as "relações". Para o autor (1995, p. 10):

[...] para "conhecer" um objeto qualquer, "coisa", "entidade" ou "ser", é preciso antes "defini-lo", isto é, caracterizá-lo, revelar sua "identidade", "essência", qualidades ou atributos próprios e específicos de sua individualidade (...) Em suma, o que interessa fundamentalmente à Metafísica na consideração geral do Universo, e o que constitui seu ponto de partida em qualquer indagação, são sempre os indivíduos que compõem aquele Universo e a individualidade deles. (...) A Dialética, considera antes as relações, o "conjunto" e a "unidade" universal donde decorrem tais reações; e é nessas relações, , sejam no espaço, sejam no tempo (...), é nelas que a Dialética vai procurar e determinar os "indivíduos" e sua "individualidade" própria: o homem será caracterizado, "individualizado", em função das suas relações biológicas, sociais, etc.; tanto quanto os elementos constituintes da matéria serão caracterizados e individualizados em função do "conjunto" (...) a que pertencem e fora do qual não têm "realidade", não têm sentido.

O conceito de "relações" apresentado por este autor refere-se às relações no âmbito da lógica dialética. Implica captar o movimento entre os polos constitutivos de cada relação. As especificidades que compõem o movimento entre os polos envolvidos se explicitam em função de categorias da lógica dialética. Tais categorias são: "fenômeno e essência"; "causa e efeito"; "necessidade e casualidade"; "lei"; "conteúdo e forma"; "possibilidade e realidade"; "singular, particular e universal"; "abstrato e concreto"; "lógico e histórico".

Esse autor vai ressaltar que até mesmo a Matemática com sua aparente imagem de conhecimento metafísico restrito às suas ideias e conceitos é também um conhecimento fruto de relações provenientes da realidade objetiva. Para o autor (1952, p. 197) "a Matemática tem por objeto essencialmente relações, ou seja, é uma ciência das mais favoráveis ao ensino do pensar por relações". O constructo teórico que 
aparece de forma imediata como abstrações matemáticas estéreis é, na verdade, criado em função da necessária correspondência com os fatos da realidade objetiva.

Sobre a Geometria, por exemplo, a ideia defendida por esse autor de evidenciar "relações" implica uma perspectiva diferente da usualmente explorada nas aulas de geometria. Da explicação de formas geométricas encontradas na natureza, inverte-se para as relações que definem as formas geométricas. Segundo esse autor (1952, p. |19):

[...] assim os polígonos, cuja conceituação é estimulada e condicionada pelos procedimentos de demarcação e medição de terrenos, fazem-se figuras geométricas (isto é, se conceituam) em consequência de tis procedimentos em que as medições e o estabelecimento de relações entre as medidas procedem a concepção das figuras propriamente; concepção essa que resulta de tal relacionamento, e não constitui, como se pretende geralmente, o ponto de partida dele. Em outras palavras, não é da consideração das figuras que se partiu historicamente para a determinação de suas propriedades ou relações: a marcha foi em sentido contrário, das propriedade para as figuras.

Referindo-se a um "retângulo", afirma (1952, p. 121$)$ :

[...] o conceito de retângulo se formou construtivamente a partir de suas propriedades (ou relações que implica); e a figura retângulo, representada depois na imaginação, ou reproduzida numa planta topográfica, será uma resultante daquela construção; não sua inspiradora. Não será a imagem concreta de retângulos porventura existentes na Natureza (e muito menos, está claro, no mundo "ideal" de Platão e dos idealistas em geral); nem deriva de formas inexplicavelmente configuradas pela imaginação: é uma construção, uma elaboração conceptual realizada pela sistematização de relações reveladas pela experiência adquirida progressivamente no curso dos atos praticados durante as tentativas de demarcação e medição que se ensaiaram sucessivamente até dar com a solução mais conveniente. (...) "Retângulo" é um conceito, um sistema conceptual, que como todo sistema conceptual, constitui m conjunto de relações.

Prado, Jr ( 1952 ) continua sua análise para os demais tópicos matemáticos. Destaca a caracterização dos polos relacionais que compõem determinado tópico matemático (por exemplo, o "cálculo diferencial e integral", as "geometrias", a saber, a euclidiana, a analítica, a descritiva etc.) possibilitando assim, grande contribuição para se pensar em procedimentos de ensino que promovam tais relações.

Apresentadas as considerações sobre Prado Jr (1 952), passamos agora a apresentar uma reflexão sobre as categorias do materialismo histórico-dialético que têm norteado as pesquisas desenvolvidas pelo autor deste artigo (as categorias do lógico e do histórico; do abstrato e do concreto e as categorias do singular, particular e universal).

\section{I A categoria do lógico e do histórico: implicações para o ensino da matemática}

A relação dialética entre o lógico e o histórico é relevante na elaboração e execução de procedimentos de ensino na óptica da PHC. Saviani (2003, p. 09) destaca essa relação (item c, da citação abaixo) quando afirma: 
[...] a tarefa a que se propõe a pedagogia histórico-crítica em relação à educação escolar implica: a) identificação das formas mais desenvolvidas em que se expressa o saber objetivo produzido historicamente, reconhecendo as condições de sua produção e compreendendo as suas principais manifestações, bem como as tendências atuais de transformação. b) conversão do saber objetivo em saber escolar, de modo que se torne assimilável pelos alunos no espaço e tempo escolares. c) provimento dos meios necessários para que os alunos não apenas assimilem o saber objetivo enquanto resultado, mas apreendam o processo de sua produção, bem como as tendências de sua transformação.

O "saber objetivo enquanto resultado" é a lógica do produto, a forma mais desenvolvida do saber, mas um ensino que privilegia apenas a lógica do produto é um ensino reduzido a enfatizar fórmulas matemáticas; é um ensino tradicional ou tecnicista. Saviani (2003) aponta para que os alunos também se apropriem do "processo de sua produção, bem como as tendências de sua transformação". Trata-se do desenvolvimento histórico. Mas seria toda a história do desenvolvimento do conceito? Não. Trata-se dos aspectos essenciais.

Segundo Duarte (1987, p. 25) "compreender o desenvolvimento histórico do objeto estudado não significa conhecer toda a história factual que o antecede". Tendo como referência Engels (s/d), Volpe (1984), Marx (1983), Duarte (1987, p. 29) conclui que "o lógico é o ponto de partida e de referência para a seleção das etapas essenciais do desenvolvimento do histórico, mas essas etapas não se encontram direta e imediatamente expressas no lógico."

A lógica do produto revela e esconde a lógica do processo. Revela, pois é síntese dos aspectos históricos essenciais. A investigação histórica inicia-se pelo estudo do desenvolvimento histórico dos aspectos iniciais que compõem a lógica do produto, em outras palavras, os aspectos essenciais que estão no corpo teórico que define o produto conceitual matemático a ser apropriado pelo aluno no processo de ensino. No decorrer da investigação histórica, revelam-se aspectos fundamentais para se entender a lógica constituída no produto, aspectos que podem estar sendo negligenciados e que, recuperados, permitem a compreensão efetiva de sua lógica final. Sob este prisma, a lógica do produto esconde aspectos da lógica do processo.

Duarte (1987, p. 32) delineia o conceito de "sequências lógico-históricas de ensino". Este conceito é referência para toda pesquisa que considera a relação entre o desenvolvimento histórico de um conceito com a sua apropriação no processo de ensino e de aprendizagem:

[...] tendo por base a relação dialética entre o lógico e o histórico, a sequência de ensino a ser adotada será aquela que for elaborada dentro da lógica do processo de gênese do produto, isto é, uma sequência lógico-histórica. Resumindo, as etapas de elaboração de uma sequência lógicoHistórica de ensino-aprendizagem são: a. analisar a estrutura lógica do conteúdo a ser ensinado. Essa análise fornecerá os pontos de referência para selecionar dentre os dados da história de desenvolvimento desse conteúdo, os antecedentes históricos (e não meramente cronológicos); b. com base na análise do item anterior, selecionar, da bibliografia disponível, os antecedentes históricos, isto é, as etapas essenciais da evolução daquele conteúdo; c. elaborar uma sequência lógico-histórica da evolução daquele conteúdo e tendo o conteúdo na sua etapa mais desenvolvida como ponto de referência, verificar se a sequência elaborada realmente é uma sequência lógico-histórica, isto é, se aquela é a sequência mais lógica da gênese daquele conteúdo: 
d. para que essa sequência se efetive enquanto sequência de ensino-aprendizagem é preciso verificar em que ponto dessa sequência está o conhecimento dos educandos. Muitas vezes eles já superaram algumas etapas mas de uma maneira precária, conhecem elementos isolados de etapas posteriores, sem ter ainda passado pelas etapas precedentes, etc. Muitas vezes essa verificação se dá ao longo do desenvolvimento da própria sequência com os educandos, quando então se vai detalhando mais certos passos e acelerando outros.

No Ensino da Matemática, o trabalho de Duarte (1987) é referência. Com o objetivo de realizar um ensino do sistema numérico hindu arábico e das quatro operações em alfabetizandos adultos, as sequências lógico-históricas de ensino evidenciam o importante papel da utilização do ábaco no ensino do sistema hindu arábico. Esquecido no ensino, o ábaco é etapa imprescindível na compreensão da gênese do sistema hindu arábico e deveria estar contemplado no processo de ensino, não apenas para compreensão do fato de o sistema numérico hindu arábico ser de base 10, posicional, justificar a existência do zero simbólico mas também, para a compreensão da lógica da gênese dos algoritmos das quatro operações aritméticas.

Giardinetto (2013, 2017), a partir da pesquisa de Duarte (1987) desenvolve ainda mais atividades. Dentre tais atividades ressalta-se a divisão de números maiores que uma dezena, utilizando-se de apenas um ábaco e se soma à defesa pela revalorização do papel do ábaco e de sua reutilização no ensino deste conteúdo matemático.

Ainda, em Giardinetto (2017) verifica-se a reflexão de distorções históricas no ensino deste conteúdo, possíveis de serem identificadas pela referência da relação entre o lógico e o histórico: a utilização de ábacos com hastes ou miçangas coloridas; a utilização de mais de um ábaco na execução das operações aritméticas; o uso de algoritmo de operações aritméticas na forma que hoje conhecemos, na explicação de procedimentos de cálculo de civilizações como a egípcia.

As categorias do lógico e do histórico também foram recursos metodológicos para a análise e a superação do "algebrismo", presente no ensino da geometria analítica, via compreensão do aspecto relacional entre álgebra e geometria, na gênese da geometria analítica GIARDINETTO, 1991).

Esse "algebrismo" reduz a relação entre os conceitos algébricos e os conceitos geométricos na geometria analítica a uma associação mecânica entre curva e equação com ênfase na manipulação de equações algébricas (GIARDINETTO, 2000, p. 137).

A investigação histórica revela que a lógica do produto deve refletir a relação entre álgebra e geometria, intrínseca na conceituação da geometria analítica. Dessa forma, faz ter sentido entender a geometria analítica como salto qualitativo com relação à geometria euclidiana, etapa mais complexa que abarca os conceitos geométricos euclidianos pela incorporação da dimensão quantitativa algébrica. Esse fato suscita a possibilidade de demonstração de teoremas da geometria euclidiana pela geometria analítica, aspecto completamente esquecido no ensino deste tópico da matemática (GIARDINETTO, 2005). 
Ainda outra investigação realizada, tendo como referência a dialética entre o lógico e o histórico, foi a que apontou o relevante papel do Desenho Geométrico na apropriação dos conceitos geométricos (OLIVEIRA, 2018). Através da aplicação de sequência didática específica revitalizou-se o Desenho Geométrico como importante recurso para a satisfatória aprendizagem de tópicos da Geometria não apenas identificando-se a deficiência no ensino decorrente do fim do Desenho Geométrico, mas também, a necessidade de defesa de seu retorno nas atividades escolares, pois torna o Desenho Geométrico significativo para os estudantes e melhora o processo de ensino desse eixo da Matemática.

Cumpre esclarecer que não foi apenas a referência à dialética do lógico e do histórico que motivou a pesquisa sobre o Desenho Geométrico aqui mencionada, mas também, a concepção de "ciências das relações" dada à Matemática por Prado, Jr (1952). Na verdade, o trabalho de investigação inicia da constatação dos polos da relação que compõem o tópico/conceito em questão e a investigação lógico/histórica que daí advém. Neste caso, procurou-se resgatar os aspectos relacionais entre Geometria e Desenho Geométrico (assim como na pesquisa sobre Geometria Analítica, pois partiu-se da constatação da relação entre os polos "Geometria Euclidiana" e "Álgebra") Para isso, defendeu-se a utilização do Desenho Geométrico como recurso para a aprendizagem de conceitos geométricos, pois, como diz Marmo; Marmo (1994, p. 12): “o Desenho é a Geometria gráfica”. Diante disso, há uma reciprocidade entre a Geometria e o Desenho Geométrico, uma vez que este contribui para a aprendizagem de conceitos geométricos, enquanto aquela colabora com a base teórica para resolução de situaçõesproblema (BRASIL, 1998, p. 125).

Assim, quando se constrói uma figura ou se realiza alguma construção geométrica, desenvolve-se o conceito de suas propriedades, através de suas características experienciais, não sendo somente uma cópia mecânica.

Essas construções envolvem conceitos e requerem reflexões, analogias, demonstrações, entre outros aspectos, capazes de desenvolver o pensamento abstrato e geométrico por procedimentos lógicos e sequenciais, servindo muito para a formação acadêmica e para a melhoria do processo de ensino.

Diante disso, o Desenho Geométrico proporciona uma melhor compreensão dos conceitos geométricos, contribuindo com o processo de ensino e de aprendizagem dos alunos.

\subsection{A categoria do abstrato e do concreto: implicações para o ensino da matemática}

Marx (1983, p. 219) com relação à categoria do abstrato e do concreto afirma:

[...] o concreto é concreto por ser a síntese de múltiplas determinações, logo, unidade da diversidade. É por isso que ele é para o pensamento um processo de síntese, um resultado, e 
não um ponto de partida, apesar de ser o verdadeiro ponto de partida e portanto igualmente o ponto de partida da observação imediata e da representação. $\bigcirc$ primeiro passo reduziu a plenitude da representação a uma determinação abstrata; pelo segundo, as determinações abstratas conduzem à reprodução do concreto pela via do pensamento.

A captação da realidade no pensamento se dá através de um movimento de afastamento e retorno à realidade objetiva, por meio da relação entre o abstrato e o concreto.

o concreto, em seu aspecto inicial, manifesta-se como dados empíricos da realidade objetiva imediatamente perceptível. Revela-se aparente, não anunciando em sua composição diversos aspectos e relações. O concreto, portanto, revela-se como ponto de partida e de chegada do processo de elaboração do conhecimento.

A superação da relativa imediaticidade do concreto, composto pelo conhecimento sensorial, se dá no pensamento através das abstrações. Estas são mediadoras no processo de construção do concreto no pensamento. Cumprem o papel de desvendar o concreto pela caracterização de cada parte constitutiva do seu todo e de suas relações internas, suas múltiplas determinações. O abstrato, portanto, é uma mediação entre o dado empírico e a compreensão real do todo; o concreto sensível relativamente imediato para um concreto pensado compreendido.

O conhecimento da realidade, portanto, impõem uma superação da relativa imediaticidade da representação empírica inicial. $\bigcirc$ abstrato é a negação do concreto inicial, o concreto sensório-perceptivo é o meio de se atingir o concreto real pensado. As abstrações são, portanto, mediações de um concreto caótico, para um concreto na compreensão da multiplicidade de suas partes. $\bigcirc$ grau de complexidade do conhecimento é obtido pelas abstrações de abstrações num processo de mediações crescentes, em que o mediato transforma-se em imediato, isto é, transforma-se em ponto de partida já dado, conhecido, dominado, a partir do qual serão elaboradas cadeias cada vez mais complexas de mediações. $\bigcirc$ imediato inicial, isto é, o conhecimento sensorial é negado pelo conhecimento mediato das primeiras abstrações. Estas superadas constituem-se em imediato, um imediato superior do imediato das sensações, pois, são consequências de abstrações mais ricas que as primeiras.

Quanto às implicações para o ensino da matemática, em Jardinetti (1996) destacam-se dois aspectos: é possível falar em concreticidade das abstrações matemáticas e na eficácia de materiais concreto palpáveis.

A "concreticidade das abstrações" é o momento catárquico do processo de ensino e de aprendizagem pleiteado pela PHC. A catarse, segundo Saviani (I 984, p. 75), é a "efetiva incorporação dos instrumentos culturais, transformados agora em elementos ativos de transformação social". Segundo Jardinetti (1996, p. 52) na Matemática, o momento catárquico é aquele em que:

[...] esmiuçada a lógica operatória presente nas abstrações, elas se revelam concretas. Na Matemática, quanto mais se afasta da realidade objetiva, mais organicamente se atrela a ela graças à lógica de elaboração dos conceitos que transfere a cada etapa conceitual um caráter de 
concreticidade para a etapa seguinte. Os conceitos apresentar-se-ão aos alunos repletos de significação.

Para Martins (2013, p. 292), trata-se da "efetivação da intencionalidade educativa". É a apropriação ativa, por parte do indivíduo, que passa a ver as abstrações matemáticas eivadas de concreticidade. Assim, sem mais estarem atreladas ao conhecimento empírico, as abstrações matemáticas atingem graus crescentes de complexidade. Para que sejam compreendidas, a concreticidade esperada se faz possível por procedimentos metodológicos que demonstrem a lógica do processo a partir da lógica do produto. A relação entre o abstrato e o concreto se efetiva por meio da relação entre o lógico e o histórico.

Quanto à utilização de materiais concreto-palpáveis, conforme Jardinetti ( 1996, p. 53), esta atinge êxito se retratar em sua constituição "as propriedades lógicas do conceito a ser apropriado (ou parte de tais propriedades)". A meta, desde os primeiros anos de escolarização, é garantir o acesso aos conceitos clássicos em Matemática. (GIARDINETTO, 2010). O recurso ao uso de material didático como réplicas de sólidos geométricos ou jogos, cumpre papel relevante se retratar aspectos lógicos do conceito matemático. Nesse sentido, atividades lúdicas apresentadas aos alunos na Educação Infantil têm sentido se forem instrumentos mediadores para apropriação de conceitos devendo, portanto, superar práticas espontaneístas. (GIARDINETTO; MARIANI, 2007, p. I87).

A contribuição da atividade escolar é propiciar a compreensão da realidade objetiva como síntese de múltiplas determinações, via o entendimento de cada determinação pela mediação da apropriação das formas mais desenvolvidas do conhecimento, demandadas. $\bigcirc$ acesso aos conteúdos escolares denota o acesso às objetivações para si, principalmente a ciência, a arte e a filosofia em suas formas clássicas (SAVIANI, 2003). A objetividade da realidade denota que a realidade é cognoscível. A apropriação dos conteúdos clássicos da Matemática presente na sua expressão escolar, pela atividade, de estudo, matemático, revela ser uma das "chaves" (KOSIK, 1985, p.22) para a apropriação de um dos diversos aspectos da prática social, aqueles aspectos explicados matematicamente.

O conhecimento matemático, no decorrer dos anos escolares, progressivamente se complexifica, propiciando instrumentos conceituais que contribuem para revelar cada vez mais a essência dos aspectos da realidade objetiva, superando a aparência destes. Descortina-se a realidade via abstrações de abstrações e isso ocorre, por exemplo, na dimensão geométrica, via ascensão da geometria euclidiana (ou plana, segundo os postulados euclidianos) para a geometria espacial (extensão da geometria plana para a tridimensionalidade das figuras); para a geometria analítica (inserção da álgebra e da análise matemática com a geometria euclidiana, algebrizando as figuras); para a geometria não euclidiana, com as geometrias elípticas e hiperbólica; para a geometria descritiva (método de representar objetos tridimensionais para um plano bidimensional) e a geometria diferencial ( com a inserção do cálculo diferencial no estudo da geometria). A realidade concreta, nesta perspectiva de análise, é síntese de múltiplas determinações de fórum geométrico. 


\subsection{A categoria do singular, do particular e do universal: implicações para o ensino da matemática}

A categoria do singular, particular e universal aborda a dialética da relação 'indivíduo e sociedade' com a relação 'indivíduo e genericidade' (o gênero humano).

O conceito de "gênero humano" é entendido por Duarte (2006, p. 213) como "as características humanas determinadas pelo código genético e aqueles produzidos e reproduzidos culturalmente". Segundo o referido autor (idem, p. 09), como tal expressa "o resultado da história social humana" (DUARTE, 2013, p. 09). Retrata, portanto, o grau de universalidade atingido no tempo histórico objetivamente presente.

Cada indivíduo, em sua singularidade, se relaciona com a universalidade do gênero humano via circunstâncias particulares, daí a categoria do 'particular'.

Cada indivíduo apresenta-se como "único" numa composição de múltiplas determinações. Mas essa composição não é intrinsecamente "autêntica"; é influenciada pela apropriação de objetivações eivadas de valores, conhecimentos, ideias constituídas pela universalidade do gênero humano. São as circunstâncias histórico-sociais que determinam o quanto das objetivações que compõem o universal, o indivíduo tem acesso e a qualidade desse acesso. $O$ indivíduo resulta da "relação entre o indivíduo (o singular) e o gênero humano (o universal) se concretizando na relação que o indivíduo tem com a sociedade (o particular)" (MARTINS, 2006, p.03). A relação indivíduo-sociedade só pode ser entendida como uma relação submetida a uma outra mais ampla, a saber, a relação do homem com o gênero humano, o que inclui, necessariamente, a relação de cada individuo singular com as objetivações humanas.

Entretanto, cumpre observar que na sociedade capitalista, constata-se haver um distanciamento entre as possibilidades do homem singular e as possibilidades existentes do gênero humano. $\bigcirc$ indivíduo, em sua singularidade, não se percebe como parte da universalidade do gênero humano em formação, assim como não percebe as objetivações da realidade que o compõem como parte dessa universalidade. Consequentemente, segundo Oliveira (2005, p. 32):

\footnotetext{
A categoria "sociedade" é, de modo geral e sem grandes esforços mentais, concebida como sendo o polo que representa o coletivo, o mais amplo, o universal, já que essa categoria ("sociedade") é algo mais imediatamente percebido do que a categoria "gênero humano". Nessa sequência de raciocínio baseada na obviedade, na imediaticidade do que é perceptível, a relação indivíduosociedade passa a ser a relação considerada nas análises como se ela correspondesse à relação singular-universal. Obviamente, como consequência imediata dessa escolha, a categoria de gênero humano fica descartada. Como esse processo é impulsionado pelo óbvio, esse descartar nem chega a ser percebido por muitos.
}

Importante tecer algumas considerações frente às implicações para a Educação Matemáticas. 
O conhecimento matemático que um indivíduo domina, é a particularidade como a universalidade se apresenta diante de circunstâncias próprias das desigualdades sociais.

São muito conhecidas pesquisas de cunho etnográfico (por exemplo, em Duarte (2004) e Gerdes (2007)) em que se verifica em indivíduos em diferentes práticas de suas profissões, o uso do conhecido "teorema de Pitágoras". Trata-se de um exemplo da relação entre a matemática produzida em contexto social específico (o particular) e sua versão escolar sistematizada pelo Teorema de Pitágoras (o universal), pois, a relação matemática que hoje recebe o nome de "Teorema de Pitágoras" se fazia presente no âmbito de uma produção específica, entre tantas outras práticas ao longo da história.

O problema de tais pesquisas é que identificam o indivíduo sem a dimensão de particularidade e, com isso, não associam à matemática universal em construção pelo gênero humano. Como adverte Mezhúiev (1980, p. 139) trata-se de um pensamento "simplificado que tras los árboles no ve el bosque, tras la diversidad no ve la unidad, tras las diferencias no ve el sentido y el contenido universales". A matemática emergida da singularidade dos indivíduos pesquisados é, na verdade, a particularidade como a universalidade se apresenta diante de circunstâncias próprias das desigualdades sociais.

E mais, práticas sociais em contextos sociais específicos evidenciam a particularidade de um momento processual da historicidade formadora do gênero humano. Saviani (1985, p. 122) afirma que "o que diferencia uma cultura de outra é a direção seguida pelo processo cultural; é, em suma, o tipo, as características de que se revestem os instrumentos, idéias e técnicas." Portanto, cumpre entender a direção do processo histórico realizada pela formação do gênero humano. Uma "matemática" presente em uma determinada comunidade no Brasil, por exemplo, uma particular medição, uma forma particular de cálculo, não abordada na escola, carrega na história dos processos de imigração da comunidade investigada, práticas matemáticas em seus países de origens em tempos passados. Entendendo esse fato como similaridade na diversidade constituída, cumpre resgatar essas particulares direções do processo histórico.

\section{CONCLUSÃO}

As considerações aqui apresentadas retratam um enorme desafio, pois, imprimem um olhar diferenciado frente ao ensino de Matemática atualmente realizado.

É instigante pensar um ensino que aponte o processo de incorporação por superação na gênese dos tópicos matemáticos bem como destacar aqueles tópicos que acrescentam outro olhar investigativo matemático sobre a parcela da realidade em investigação. Como afirma Kosik (I 985, p. 22) a atividade (no caso, atividade matemática) "revela-se a chave para a apropriação dos diversos aspectos da prática social". 
grau de complexidade hoje atingido pelo desenvolvimento da Matemática gera uma maior complexidade à escola na realização do processo pedagógico de garantir as formas clássicas, o "clássico" em Matemática (SAVIANI, 2003; GIARDINETTO, 20I0).

A depuração daquilo que é essencial ressalta a importância da compreensão da dialética do lógico e do histórico, a partir da identificação dos polos relacionais que compõem o tópico, conceito matemático. Ao mesmo tempo, ressalta a dinamicidade da relação concreto e abstrato, pois configura o constante movimento da dialética concreto sensorial / mediação abstrata / concreto síntese de múltiplas determinações.

Por fim, a dialética singular/particular/universal, entre outros aspectos, instrumentaliza o indivíduo para a suspensão de formas de alienação que imprimem tentativas de não compreensão do caráter ativo e transformador da realidade na edificação do gênero humano, de sorte a entender a importância da educação escolar como instituição socializadora do saber sistematizado (SAVIANI, 2003, p. | 4)

\section{REFERÊNCIAS}

BRASIL. Parâmetros curriculares nacionais - terceiro e quarto ciclos do ensino fundamental: matemática. Brasília, DF: MEC/SEF, 1998.

CARAÇA, Bento de Jesus. Conceitos fundamentais da matemática. Portugal: Livraria Sá da Costa Editora. 1984.

DUARTE, Newton. Por uma educação que supere a falsa escolha entre etnocentrismo ou relativismo cultural. In: DUARTE, N. \& FONTE, Sandra S. dela (Orgs.). Arte, conhecimento e paixão na formação humana: sete ensaios de pedagogia histórico-crítica. (pp. I 01 - 120). Campinas, SP, Autores Associados, 2010.

DUARTE, Newton. Education as mediation between the individual's everyday life and the historical construction of society and culture by humankind. In: SAWCHUK, P. H., DUARTE, N.,

ELHAMMOUMI, M. Critical perspectivies on activity: explorations across education, work and everday life. ( pp. 21 I- 292). USA, Cambridge University Press, 2006.

DUARTE, Newton. O Ensino de Matemática na Educação de Adultos. São Paulo: Cortez: Autores Associados, 1989.

DUARTE, Newton. A relação entre o lógico e o histórico no ensino da matemática elementar. Dissertação (Mestrado). UFSCar. Centro de Educação e Ciências Humanas, Universidade Federal de São Carlos, São Carlos, SP, 1987.

DUARTE, Cláudia Glavann. Implicações curriculares a partir de um olhar sobre o "mundo da construção. In: KNIJNIK, G.; WANDERER, F.; OLIVEIRA, C. J de. (org.). Etnomatemática: currículo e formação de professores. (pp. I83-202). Santa Cruz do Sul: EDUNISC, 2004.

ENGELS, Friedrich. A 'contribuição à crítica da economia política' de Karl Marx. In: Obras escolhidas, Alfa-Ômega, SP, s/d. 
GERDES, Paulus. Etnomatemática: reflexões sobre a matemática e diversidade cultural. Lisboa: Edições Húmus, 2007.

GIARDINETTO, José Roberto Boettger. O saber escolar como parte das formas mais desenvolvidas de saber: a questão cultural na educação matemática. Revista Educação Matemática Pesquisa. (pp. 195 208). São Paulo: PUC, I4(0 I), 16, 2012.

GIARDINETTO, José Roberto Boettger. $O$ ensino da Matemática na perspectiva da pedagogia históricocrítica: sequências lógico-históricas de ensino. In ZANATA, E. M; CALDEIRA, A. M de A.; LEPRE, R. M (orgs). Cadernos de docência na educação básica I. São Paulo: Cultura Acadêmica, 2012.

GIARDINETTO, José Roberto Boettger. O conceito de saber escolar 'clássico' em Dermeval Saviani: implicações para a Educação Matemática. In: BOLEMA: Boletim de Educação Matemática. (pp. 753-773) Rio Claro, UNESP, volume 23, n. 36, 2010.

GIARDINETTO, José Roberto Boettger ; MARIANI, Janeti Marmontel. O lúdico no ensino da matemática na perspectiva vigotskiana do desenvolvimento infantil. In: ARCE, A.; MARTINS, L; M. Quem tem medo de ensinar na educação infantil? Em defesa do ato de ensinar. Caminas, SP: Editora Alínea, 2007.

GIARDINETTO, José Roberto Boettger. A relação entre o abstrato e o concreto no ensino da geometria analítica a nível do $1^{\circ}$ e $2^{\circ}$ graus. São Carlos, São Paulo: UFSCar, Dissertação, I99I.

JARDINETTI, José Roberto Boettger. $O$ abstrato e o concreto no ensino de matemática: algumas reflexões. BOLEMA: Boletim de Educação Matemática. (pp. 45-57), Rio Claro: UNESP, n. I2, 1996.

MARX, Karl. O método da economia política. In: MARX, K. Contribuição à crítica da economia política. (pp 2 I 8-226). São Paulo: Martins Fontes Editora, 1983.

MARMO, Carlos; MARMO, Nicolau. Desenho Geométrico. Rio de Janeiro, RJ: Scipione, 1994.

MARTINS, Lígia Márcia. O desenvolvimento do psiquismo e a educação escolar. Campinas, SP: Autores Associados (Coleção Educação Contemporânea), 2013.

MARTINS, Lígia Márcia. As aparências enganam: divergências entre o materialismo histórico dialético e as abordagens qualitativas de pesquisa. In 29a Reunião Anual da ANPED, Caxambu, Minas Gerais, Grupo de Trabalho Filosofia da Educação, 01 - 17, 2006.

MEZHÚIEV, V. La cultura y la historia: el problema de la cultura en la teoría marxista de la filosofia y la historia. Moscú: Progreso, 1980.

PRADO JÚNIOR, Caio. Dialética do conhecimento: preliminares, prehistória da dialética. São Paulo: Brasiliense, 1952.

OLIVEIRA, Betty Antunes. A dialética do singular-particular-universal. In: ABRANTES, Angelo Antonio; SILVA, Nilma Renildes da; MARTINS, Sueli Terezinha Ferreira (Orgs.). Método histórico-social na psicologia social. (pp. 25-5I). Petrópolis, RJ: Vozes, 2005. 
OLIVEIRA, Robinson Neres de. Contribuição do Desenho Geométrico na apropriação de conceitos geométricos. Bauru: Programa de Pós-Graduação em docência para a educação básica, 2018 (Dissertação, Mestrado Profissional).

SAVIANI, Dermeval. Pedagogia histórico-crítica. Campinas, SP: Autores Associados, 2003.

SAVIANI, Dermeval. Escola e democracia. São Paulo, Cortez; Campinas, Autores Associados, 1984.

VERA, Francisco. Psicogénesis del razonamiento matemático. Buenos Aires: Editorial Poseidon, 1947.

VOLPE, Galvano della. A lógica como ciência histórica. Lisboa: edições 70, 1984. 